\title{
Clinical utility, safety, and tolerability of ezogabine (retigabine) in the treatment of epilepsy
}

This article was published in the following Dove Press journal:

Drug, Healthcare and Patient Safety

25 July 2012

Number of times this article has been viewed

\author{
Michael A Ciliberto \\ Judith LZ Weisenberg \\ Michael Wong \\ Department of Neurology, \\ Washington University School \\ of Medicine, St Louis, MO, USA
}

Correspondence: Michael Wong Department of Neurology, Campus Box 8I II, Washington University School of Medicine, 660 S Euclid Avenue, St Louis, MO 63II0, USA

$\mathrm{Tel}+\mathrm{I} 3$ | $436287 \mid 3$

Fax + I 3143629462

Email wong_m@wustl.edu

\begin{abstract}
One-third of patients with epilepsy continue to have seizures despite current treatments, indicating the need for better antiseizure medications with novel mechanisms of action. Ezogabine (retigabine) has recently been approved for adjunctive treatment of partialonset seizures in adult patients with epilepsy. Ezogabine utilizes a novel mechanism of action, involving activation of specific potassium channels. The most common side effects of ezogabine are shared by most antiseizure medications and primarily consist of central nervous system (CNS) symptoms, such as somnolence, dizziness, confusion, and fatigue. In addition, a small percentage of patients on ezogabine experience a unique adverse effect affecting the bladder, which results in urinary hesitancy; thus, patients on ezogabine should be monitored carefully for potential urological symptoms. Overall, ezogabine appears to be well tolerated and represents a reasonable new option for treating patients with intractable epilepsy.
\end{abstract}

Keywords: antiepileptic drug, seizure, bladder, potassium channels

\section{Introduction}

Epilepsy is a common disease with a cumulative lifetime risk of at least $3 \% .{ }^{1}$ It is associated with significant morbidity and mortality, as well as decreased quality of life in a variety of social, educational, and vocational measures..$^{2-4}$ Specifically, mortality has been demonstrated to be up to threefold higher in developed countries. ${ }^{5}$ Further, adults with seizures are at risk for lower levels of education, higher rates of unemployment, and psychological and physical ailments. ${ }^{6}$ A number of new antiseizure medications have been developed and marketed in the last two decades. Despite these new therapies, medically intractable epilepsy, defined as persistent seizures after an adequate trial of two appropriate antiseizure medications, continues to occur in approximately onethird of cases. ${ }^{7,8}$ This makes the development of antiseizure medications with novel mechanisms of action an important goal to further broaden the possible success in intractable epilepsy of various etiologies. However, with novel mechanisms of action there is a risk of unique side effects.

One of these new antiseizure medications with a novel mechanism of action is ezogabine (EZG). EZG is an ethyl $N$-(2-amino-4-\{[(4-fluorophenyl)methyl]amino $\}$ phenyl) (Figure 1) and is known by the international nonproprietary name of "retigabine" in Europe and most of the world. This drug was recently approved by the European Medicines Agency and the US Food and Drug Administration (FDA) for adjunctive treatment of partial-onset seizures in adults. It appears to work by a unique mechanism of action compared with other currently available antiepileptic drugs. A number of 


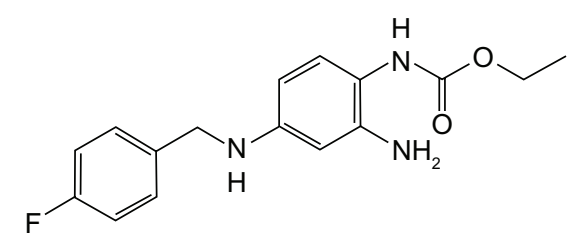

Figure I Chemical structure of ezogabine.

other recent reviews have also highlighted different aspects of EZG ${ }^{9-13}$ but this review focuses especially on the adverse effects of EZG.

\section{Mechanism of action}

First developed through the National Institutes of Health Antiepileptic Drug Development program after the identification of a structural analog's (flupirtine) efficacy against seizures, EZG's mechanism of action is novel among currently available antiseizure medications. ${ }^{14}$ EZG exerts its effects on the Kv7 family of potassium channels ${ }^{15,16}$ by binding to the cytoplasmic aspects of the S5 and S6 parts of the activation gate of these potassium channels involved in the M-current. ${ }^{17,18}$ In doing so, EZG increases rates of channel opening, maintains potassium channels in the open state for longer periods of time, and alters the voltage characteristics of the cell, making channel opening more likely. ${ }^{16}$

The channels bound by EZG consist of the Kv7 homoand heteromeric subunits KCNQ2-5..$^{15,16,19}$ EZG's primary site of action is the KCNQ2/3 heteromer, ${ }^{15,16}$ which is expressed in the nervous system and accounts for its antiseizure efficacy. There is no enhancement of the potassium currents mediated by the KCNQ1 channel subunit, which is found primarily in cardiac tissue ${ }^{18}$ and also in the gastrointestinal system and brain. ${ }^{20}$ However, KCNQ4 and KCNQ5 potassium channels are activated by EZG and may be found in cochlear hair cells ${ }^{21}$ or smooth muscle. ${ }^{22}$ EZG causes relaxation of smooth muscle in the bladder, which probably accounts for the adverse effects of EZG on urinary function. ${ }^{23}$

\section{Metabolism-drug interactions}

EZG is absorbed rapidly after oral administration, with a peak plasma concentration at 1.5 hours after ingestion. ${ }^{24}$ EZG is metabolized primarily by acetylation and glucuronidation in the liver and is subsequently eliminated by renal excretion. ${ }^{25,26}$ Due to this dual metabolism, it is recommended that individuals with low creatinine clearance ( $<50 \mathrm{~mL} / \mathrm{min}$ ), undergoing hemodialysis, or with moderate to severe hepatic impairment start at a lower starting dose
$(50 \mathrm{mg} / \mathrm{d})$ and titrate to a lower maximum dose $(600 \mathrm{mg} / \mathrm{d}$ for renal failure or severe hepatic impairment; $750 \mathrm{mg} / \mathrm{d}$ for moderate hepatic impairment). In patients $66-81$ years of age, it has been noted that EZG clearance was diminished compared with younger study participants (18-40 years of age) and the authors attributed this to the normal decrease in creatinine clearance that occurs with age. No side effects from this difference were noted. ${ }^{27}$

As in vitro studies have demonstrated little or no potential for EZG to inhibit or induce the major cytochrome, ${ }^{28} \mathrm{P} 450$ isoenzymes, minimal drug interactions of clinical significance have been reported. EZG does not interact with oral contraceptive agents. ${ }^{29}$ Moreover, it seems to be well tolerated in individuals taking other antiseizure medications as well, with minimal direct interactions. While EZG and lamotrigine had reciprocal effects on renal clearance, both drugs were tolerated equally well alone and in combination, thus these interactions were not thought clinically significant. ${ }^{30}$ No clinically significant interactions have been found between EZG and propofol, valproate, or imipramine ${ }^{26}$ and an in vivo study has demonstrated lack of interaction between phenobarbitone and EZG..$^{31}$ In clinical studies, no significant pharmacokinetic effect has been seen on phenytoin, carbamazepine, valproic acid or topiramate. ${ }^{32}$ Overall, EZG has few clinically significant interactions with other pharmaceutical agents.

\section{Efficacy}

Three double-blind placebo-controlled multicenter trials have taken place investigating the efficacy of EZB in adults with medically intractable partial-onset epilepsy as add-on therapy in combination with other antiepileptic medications. ${ }^{33-35}$ A recent paper has reported an integrated analysis of these three controlled trials. ${ }^{36}$ After pooling data from the three studies, 1240 patients were included, with 813 patients randomized to EZG and 427 to placebo. In all trials, after an initial 8-week baseline phase, patients were randomized to placebo or EZB (titrated to 600,900 , or $1200 \mathrm{mg} /$ day, depending on the trial), followed by an 8-12-week maintenance phase. Two primary efficacy measures were used: (1) responder rate, defined as the percentage of patients experiencing a $\geq 50 \%$ reduction in seizure frequency compared with the baseline phase; and (2) the percent change in partial seizure frequency. A number of secondary efficacy endpoints were also assessed, including more specific categorization of seizure frequency reduction rates and the proportion of seizure-free days and seizure-free patients.

Analysis of the integrated data found statistically significant effects of EZB on both primary efficacy 
measures. ${ }^{36}$ Responder rates ( $\geq 50 \%$ reduction in seizure frequency) were $35 \%$ and $45 \%$ for EZG at 600 and $900 \mathrm{mg}$ /day, respectively, compared with $21 \%$ for placebo $(P<0.001)$ and $50 \%$ for EZG at $1200 \mathrm{mg}$ /day, compared with $24 \%$ for placebo $(P<0.001)$. Average reduction in seizure frequency was $26 \%, 37 \%$, and $39 \%$ for 600,900 , and $1200 \mathrm{mg} / \mathrm{d}$ EZG, respectively, all of which were statistically significantly greater than placebo (15\%). Similar differences were observed in various secondary endpoints. For example, the proportion of patients experiencing a $50 \%-75 \%$ or $\geq 75 \%$ reduction in seizures showed a dose-dependent increase with EZG compared with placebo. At all doses, there was a significant increase in seizure-free days with EZG compared with placebo, although the effect was modest ( $81 \%-84 \%$ for EZG vs $78 \%$ for placebo). In addition, while in the individual trials there had been no statistically significant effect of EZG on the percentage of seizure-free patients, in the pooled analysis of EZG at $1200 \mathrm{mg} / \mathrm{d}$, but not at 600 or $900 \mathrm{mg} / \mathrm{d}$, there was a statistically significant increase in the proportion of seizure-free patients during the maintenance phase $(15 \%$ with $1200 \mathrm{mg} / \mathrm{d}$ EZG vs 5\% with placebo).

Subgroup analyses did not demonstrate any differences in the magnitude of the effect of EZG based on age (18-44 years vs $>44$ years), sex, race (white vs nonwhite), region (US vs non-US), number of baseline antiseizure medications, and seizure subtypes (simple partial, complex partial, secondary generalized). Overall, these randomized placebo-controlled trials demonstrated that EZG is effective as add-on therapy for adults with intractable partial-onset epilepsy. The magnitude of the effects of EZG on seizures is similar to most other new antiseizure medications used as adjunctive therapy for intractable epilepsy and only a small percentage of patients become seizure-free on EZG.

\section{Adverse events}

Over the course of the three major placebo-controlled trials, ${ }^{33-35}$ EZG was generally quite well tolerated. Based on the pooled analysis, adverse events that were considered severe were similar in the placebo (10\%), EZG $600 \mathrm{mg} / \mathrm{d}(10 \%)$, and EZG $900 \mathrm{mg} / \mathrm{d}(12 \%)$ groups but were higher in the EZG $1200 \mathrm{mg} / \mathrm{d}$ group (20\%). ${ }^{36}$ All other adverse events were noted by investigators to be mild to moderate. Three deaths $(0.7 \%)$ related to sudden death in epilepsy, injury, and respiratory failure occurred in the 427 patients on placebo, whereas only two deaths $(0.2 \%)$ in the cumulative EZG groups due to sudden death in epilepsy and diabetic ketoacidosis occurred in the 813 patients. Discontinuation of the study due to adverse events occurred in $10 \%$, $15 \%, 24 \%$, and $28 \%$ of patients in the placebo, $600 \mathrm{mg} / \mathrm{d}$, $900 \mathrm{mg} / \mathrm{d}$, and $1200 \mathrm{mg} / \mathrm{d}$ groups, respectively. ${ }^{36}$

Reasons for discontinuation of the study and the overall most common adverse events were generally central nervous system (CNS) related (Table 1). These adverse events occurred with increasing frequency as the dose of EZG was increased. The most common side effects included dizziness and somnolence and, to a lesser extent, confusion, fatigue, and asthenia. ${ }^{33-35}$ Porter et $\mathrm{a}^{33}$ noted speech difficulties in no patients in the placebo arms and five (5\%), twelve $(12.6 \%)$, and $17(16 \%)$ patients in the $600 \mathrm{mg} / \mathrm{d}, 900 \mathrm{mg} / \mathrm{d}$, and $1200 \mathrm{mg} / \mathrm{d}$ arms, respectively.

EZG has been noted to decrease gastrointestinal smooth muscle contractility. ${ }^{37,38}$ Constipation was not mentioned

Table I Adverse effects of ezogabine reported in at least $5 \%$ of patients with intractable partial seizures in placebo-controlled add-on clinical trials

\begin{tabular}{|c|c|c|c|c|}
\hline & $\begin{array}{l}\text { Placebo, } \\
n=427(\%)\end{array}$ & $\begin{array}{l}\text { Ezogabine } 600 \mathrm{mg} / \mathrm{d} \text {, } \\
\mathrm{n}=28 \mathrm{I}(\%)\end{array}$ & $\begin{array}{l}\text { Ezogabine } 900 \mathrm{mg} / \mathrm{d} \text {, } \\
\mathrm{n}=273(\%)\end{array}$ & $\begin{array}{l}\text { Ezogabine } 1200 \mathrm{mg} / \mathrm{d} \text {, } \\
\mathrm{n}=\mathbf{2 5 9}(\%)\end{array}$ \\
\hline Dizziness & $38(8.9)$ & $4 \mid(14.6)$ & $64(23.4)$ & $84(32.4)$ \\
\hline Somnolence & 51 (II.9) & $43(15.3)$ & $67(24.5)$ & $69(26.6)$ \\
\hline Confusion & II (2.6) & $12(4.3)$ & $21(7.7)$ & $42(16.2)$ \\
\hline Headache & $68(15.9)$ & $34(12.1)$ & $47(17.2)$ & $39(15.1)$ \\
\hline Fatigue & $25(5.9)$ & $45(16)$ & $40(14.7)$ & $34(13.1)$ \\
\hline Coordination disturbance & $12(2.8)$ & $14(5)$ & $14(5.1)$ & $30(11.6)$ \\
\hline Blurred vision & $9(2.1)$ & $5(1.8)$ & $12(4.4)$ & $27(10.4)$ \\
\hline Memory impairment & II (2.6) & $7(2.5)$ & $15(5.5)$ & $24(9.3)$ \\
\hline Vertigo & $9(2.1)$ & $22(7.8)$ & $21(7.7)$ & $24(9.3)$ \\
\hline Nausea & $22(5.2)$ & $18(6.4)$ & $17(6.2)$ & $22(8.5)$ \\
\hline Attention disturbance & $4(<1)$ & $17(6)$ & $15(5.5)$ & $17(6.6)$ \\
\hline Urinary/renal & $55(12.9)$ & $38(13.5)$ & $35(12.8)$ & $65(25.1)$ \\
\hline Discontinued due to adverse events & $39(9.1)$ & $4 \mid(14.6)$ & $65(23.8)$ & 73 (28.2) \\
\hline Death & 3 & 1 & 0 & I \\
\hline
\end{tabular}

Adapted from Epilepsy Res. Porter et al; Retigabine as adjunctive therapy in adults with partial-onset seizures: integrated analysis of three pivotal controlled trials. (๐ 2012, with permission from Elsevier. ${ }^{36}$ 
in two studies ${ }^{33,35}$ but occurred in three $(2 \%)$ patients in the placebo arm and nine (5.9\%) patients in the $1200 \mathrm{mg} / \mathrm{d}$ group French et al's study. ${ }^{34}$ Alterations in liver enzyme levels were noted rarely but were transient and did not require discontinuation from the studies. ${ }^{33-35}$ No changes in electrocardiography have been reported. Adverse events related to cardiac abnormalities were similar in the placebo (4\%) and EZG (5\%) groups.

While most of the reported side effects of EZG are similar to many other antiseizure medications in that they most commonly affect the CNS, EZG has one relatively unique and specific adverse effect, which is related to urinary function. ${ }^{37}$ EZG had initially been noted to relax rat bladders ${ }^{39}$ as well as decrease bladder tension and contraction amplitude. ${ }^{40}$ As a result of this basic science data, urinary adverse events were recorded during the placebo-controlled trials. In Brodie et al's trial, ${ }^{35}$ three patients were discharged from these trials for urinary symptoms, although the groups to which these patients were assigned were not delineated: one for nephritis and two for urinary hesitation. French et $\mathrm{al}^{34}$ reported nine $(5.9 \%)$ patients in the $1200 \mathrm{mg} / \mathrm{d}$ arm and one $(0.7 \%)$ in the placebo arm with urinary hesitation and eight $(5.2 \%)$ patients in the $1200 \mathrm{mg} / \mathrm{d}$ arm and two (1.3\%) in the placebo arm with dysuria. In the pooled analysis, urinary or renal symptoms were reported in the EZG $1200 \mathrm{mg} / \mathrm{d}$ group (25\%) almost twice as frequently as in the placebo $(13 \%)$ group, although similar rates as in the placebo group were reported with $600 \mathrm{mg} / \mathrm{d}(14 \%)$ and $900 \mathrm{mg} / \mathrm{d}(13 \%) .{ }^{35,36}$ Other urinary symptoms and signs reported included urinary tract infections, polyuria, hematuria, proteinuria, and chromaturia. These adverse events were noted to diminish with time on the medication and were noted to be mild to moderate. Very few cases led to discontinuation ( $1 \%$ for both EZG and placebo). Due to the urinary symptoms, the FDA has required postmarketing analysis and recording of urinary symptoms.

Some data from the open-label extension trial have now been published in a recent review. ${ }^{37}$ There continues to be no evidence of direct renal adverse events, although one participant did have reversible renal failure related to obstructive uropathy. ${ }^{37}$ Of note, four participants have now been reported with nephrolithiasis in the $1200 \mathrm{mg} / \mathrm{d}$ group. ${ }^{37}$ However, based on the overall incidence of nephrolithiasis in the USA and EZG's mechanism of action, it is not felt that ezogabine is an independent risk factor for nephrolithiasis at this time. Urinary crystals with an appearance similar to bilirubin have been reported in some participants. ${ }^{37}$ This could result in an abnormal urinalysis result but does not appear to be related to a risk for nephrolithiasis. Overall, it would seem prudent to monitor any patients on EZG for urologic symptoms and be cautious with those with risk factors for urinary obstruction.

No data are available on the safety of EZG use during pregnancy. As such, EZG is a pregnancy class $\mathrm{C}$ drug. In addition, there is a lack of established safety data on infants of breastfeeding mothers on EZG.

\section{Other clinical applications}

A variety of additional clinical applications beyond epilepsy have been proposed for EZG. These include in neuromyotonia, ${ }^{41}$ neuropathic pain, ${ }^{42,43}$ mania, and addiction to psychostimulants. ${ }^{44}$ Other rodent models have demonstrated a possible anti-dystonic effect. ${ }^{45} \mathrm{An}$ in vitro study has demonstrated a possible anxiolytic effect of EZG. ${ }^{46}$ However, these other applications are still under investigation.

\section{Discussion and conclusion}

Epilepsy, despite several new medications that have been developed in the last few decades, continues to be refractory to medications in one-third of patients and can be a significant cause of morbidity and mortality. EZG is a new antiseizure drug with a novel mechanism of action. It is a potassiumchannel activator primarily active in the CNS, with alternate sites of action in the urinary bladder, gastrointestinal smooth muscle, and vascular smooth muscle. ${ }^{47,48}$

EZG has proven efficacy and is approved both in the USA and Europe for treatment of adults with intractable partialonset epilepsy. Given its novel mechanism of action, there is hope that EZG may be more effective for some patients with intractable epilepsy than other available antiseizure medications, although, overall, the efficacy data are fairly comparable to studies of other drugs in intractable patients. Early data demonstrate minimal interaction with medications other than lamotrigine and those interactions were deemed to be clinically insignificant. ${ }^{30}$

EZG is generally well tolerated and is rarely discontinued due to adverse events. The number of reported adverse events is also likely to be influenced by the forced fast titration schedule deemed necessary by the authors of the placebocontrolled trials. Most of these adverse events were CNS related, such as somnolence and fatigue.

However, EZG has a novel adverse effect on the urinary tract - specifically, on the urinary bladder - both in animal models and in human trials. Urinary or secondary renal adverse effects are collectively relatively common, occurring in about $25 \%$ of patients in the highest-dose EZG group..$^{36,37}$ Symptoms from urinary adverse events were usually noted 
to be minor or moderate, sometimes only involving laboratory abnormalities on urinalysis and rarely leading to discontinuation from the trial. However, urinary hesitancy and retention can be clinically significant problems. Thus, due to this novel side effect and the lack of a significant quantity of long-term data as to the severity and prevalence of urinary adverse events, the FDA has recommended a risk evaluation and mitigation strategy to further track the use of EZG in this regard. Overall, no long-term data currently exist as to the safety of EZG.

\section{Disclosure}

The authors declare no conflicts of interest in this work.

\section{References}

1. Hesdorffer DC, Logroscino G, Benn EK, Katri N, Cascino G, Hauser WA. Estimating risk for developing epilepsy: a population-based study in Rochester, Minnesota. Neurology. 2011;76(1):23-27.

2. Nadkarni J, Jain A, Dwivedi R. Quality of life in children with epilepsy. Ann Indian Acad Neurol. 2011;14(4):279-282.

3. Baca CB, Vickrey BG, Vassar SD, Berg AT. Seizure recency and quality of life in adolescents with childhood-onset epilepsy. Epilepsy Behav. 2012;23(1):47-51

4. Sillanpää M, Shinnar S. Long-term mortality in childhood-onset epilepsy. N Engl J Med. 2010;363(26):2522-2529.

5. Forsgren L, Hauser WA, Olafsson E, Sander JW, Silanpää M, Tomson T. Mortality of epilepsy in developed countries: a review. Epilepsia. 2005;46 Suppl 11:18-27.

6. Strine TW, Kobau R, Chapman DP, Thurman DJ, Price P, Balluz LS. Psychological distress, comorbidities, and health behaviors among US adults with seizures: results from the 2002 National Health Interview Survey. Epilepsia. 2005;46(7):1133-1139.

7. Elger CE, Schmidt D. Modern management of epilepsy: a practical approach. Epilepsy Behav. 2008;12(4):501-539.

8. Kwan P, Brodie MJ. Early identification of refractory epilepsy. $N$ Engl J Med. 2000;342(5):314-319.

9. Rheims S, Ryvlin P. Retigabine for partial onset seizures. Expert Rev Neurother. 2012;12(5):509-517.

10. Large CH, Sokai DM, Nehlig A, et al. The spectrum of anticonvulsant efficacy of retigabine (ezogabine) in animal models: implications for clinical use. Epilepsia. 2012;53(3):425-436.

11. Rejdak K, Luszczki JJ, Błaszczyk B, Chwedorowicz R, Czuczwar SJ. Clinical utility of adjunctive retigabine in partial onset seizure in adults Ther Clin Risk Manag. 2012;8:7-14.

12. Stafstrom CE, Grippon S, Kirkpatrick P. Ezogabine (retigabine). Nat Rev Drug Discov. 2011;10(10):729-730.

13. Weisenberg JL, Wong M. Profile of ezogabine (retigabine) and its potential as an adjunctive treatment for patients with partial-onset seizures. Neuropsychiatr Dis Treat. 2011;7:409-414.

14. Rostock A, Tober C, Rundfeldt C, et al. D-23129: a new anticonvulsant with a broad spectrum activity in animal models of epileptic seizures. Epilepsy Res. 1996;23(3):211-223.

15. Wickenden AD, Yu W, Zou A, Jegla T, Wagoner PK. Retigabine, a novel anticonvulsant, enhances activation of $\mathrm{KCNQ} 2 / \mathrm{Q} 3$ potassium channels. Mol Pharmacol. 2000;58(3):591-600.

16. Main MJ, Cryan JE, Dupere JR, Cox B, Clare JJ, Burbidge SA. Modulation of KCNQ2/3 potassium channels by the novel anticonvulsant retigabine. Mol Pharmacol. 2000;58(2):253-262.

17. Wuttke TV, Seebohm G, Bail S, Maljevic S, Lerche H. The new anticonvulsant retigabine favors voltage-dependent opening of the Kv7.2 (KCNQ2) channel by binding to its activation gate. Mol Pharmacol. 2005;67(4):1009-1017.
18. Rundfeldt C, Netzer R. The novel anticonvulsant retigabine activates M-currents in Chinese hamster ovary-cells tranfected with human KCNQ2/3 subunits. Neurosci Lett. 2000;282(102):73-76.

19. Tatulian L, Delmas P, Abogadie FC, Brown DA. Activation of expressed KCNQ potassium currents and native neuronal M-type potassium currents by the anti-convulsant drug retigabine. J Neurosci. 2001;21(15):5535-5545.

20. Jentsch TJ. Neuronal KCNQ potassium channels: physiology and role in disease. Nat Rev Neurosci. 2000;1(1):21-30.

21. Kharkovets T, Dedek K, Maier H, et al. Mice with altered KCNQ4 K+ channels implicate sensory outer hair cells in human progressive deafness. EMBO J. 2006;25(3):642-652.

22. Greenwood IA, Ohya S. New tricks for old dogs: KCNQ expression and role in smooth muscle. Br J Pharmacol. 2009;156(8):1196-1203.

23. Jepps TA, Greenwood IA, Moffatt JD, Sanders KM, Ohya S. Molecular and functional characterization of $\mathrm{Kv} 7 \mathrm{~K}+$ channel in murine gastrointestinal smooth muscles. Am J Physiol Gastrointest Liver Physiol. 2009;297(1):G107-G115.

24. Ferron GM, Paul J, Fruncillo R, et al. Multiple-dose, linear, doseproportional pharmacokinetics of retigabine in healthy volunteers. J Clin Pharmacol. 2002;42(2):175-182.

25. McNeilly RJ, Torchin CD, Anderson LW, Kapetanovic IM, Kupferberg HJ, Strong JM. In vitro glucuronidation of D-23129, a novel anticonvulsant, by human liver microsomes and liver slices. Xenobiotica. 1997;27(5):431-441.

26. Borlak J, Gasparic A, Locher M, Schupke H, Hermann R. $\mathrm{N}$-Glucuronidation of the antiepileptic drug retigabine: results from studies with human volunteers, heterologously expressed human UGTs, human liver, kidney, and liver microsomal membranes of Crigler-Najjar type II. Metabolism. 2006;5(6):711-721.

27. Hermann R, Ferron GM, Erb K, et al. Effects of age and sex on the disposition of retigabine. Clin Pharmacol Ther. 2003;73(1):61-70.

28. Hempel R, Schupke H, McNeilly PJ, et al. Metabolism of retigabine (D-23129), a novel anticonvulsant. Drug Metab Dispos. 1999;27(5): 613-622.

29. Ferron GM, Paul J, Richards L, Getsy J, Troy S. Retigabine does not alter the pharmacokinetics of a low dose oral contraceptive in women. Neurology. 2001;56(Suppl 3):A335-A336.

30. Hermann R, Knebel NG, Niebch G, Richards L, Borlak J, Locher M. Pharmacokinetic interaction between retigabine and lamotrigine in healthy subjects. Eur J Clin Pharmacol. 2003;58(12):795-802.

31. Ferron GM, Patat A, Parks V, Rolan P, Troy SM. Lack of pharmacokinetic interaction between retigabine and phenobarbitone at steady-state in healthy subjects. Br J Clin Pharmacol. 2003;56(1):39-45.

32. Bialer M, Johannessen SI, Levy RH, Perucca E, Tomson T, White HS. Progress report on new antiepileptic drugs: a summary of the Ninth Eilat Conference (EILAT IX). Epilepsy Res. 2009;83(1):1-43.

33. Porter RJ, Partiot A, Sachdeo R, Nohria V, Alves WM. Randomized, multicenter, dose-ranging trial of retigabine for partial-onset seizures. Neurology. 2007;68(15):1197-1204.

34. French JA, Abou-Khalil BW, Leroy RF, et al; RESTORE 1/Study 301 Investigators. Randomized double-blind, placebo-controlled trial of ezogabine (retigabine) in partial epilepsy. Neurology. 2011;76(18):1555-1563.

35. Brodie MJ, Lerche H, Gil-Nagel A, et al; RESTORE 2 Study Group. Efficacy and safety of adjunctive ezogabine (retigabine) in refractory partial epilepsy. Neurology. 2010;75(20):1817-1824.

36. Porter RJ, Burdette DE, Gil-Nagel A, et al. Retigabine as adjunctive therapy in adults with partial-onset seizures: integrated analysis of three pivotal controlled trials. Epilepsy Res. Epub April 16, 2012.

37. Brickel N, Gandhi P, Vanlandingham K, Hammond J, Derossett S. The urinary safety profile and secondary renal effects of retigabine (ezogabine): a first-in-class antiepileptic drug that targets KCNQ (K(v) 7) potassium channels. Epilepsia. 2012;53(4):606-612.

38. Ipaveca V, Martirea M, Barreseb V, Taglialatela M, Currò D. KV7 channels regulate muscle tone and nonadrenergic noncholinergic relaxation of the rat gastric fundus. Pharmacol Res. 2011;64(4):397-409. 
39. Streng T, Christoph T, Andersson KE. Urodynamic effects of the K+ channel (KCNQ) opener retigabine in freely moving, conscious rats. J Urol. 2004;172(5 Pt 1):2054-2058.

40. Rode F, Svalø J, Sheykhzade M, Christian L, Rønn LC. Functional effects of the KCNQ modulators retigabine and XE991 in the rat urinary bladder. Eur J Pharmacol. 2010;638(1-3):121-127.

41. Shillito P, Molenaar PC, Vincent A, et al. Acquired neuromyotonia: evidence for autoantibodies directed against $\mathrm{K}+$ channels of peripheral nerves. Ann Neurol. 1995;38(5):714-722.

42. Blackburn-Munro G, Jensen BS. The anticonvulsant retigabine attenuates nociceptive behaviors in rat models of persistent and neuropathic pain. Eur J Pharmacol. 2003;460(2-3):109-116.

43. Munro G, Erichsen HK, Mirza NR. Pharmacological comparison of anticonvulsant drugs in animal models of persistent pain and anxiety. Neuropharmacology. 2007;53(5):609-618.

44. Hansen HH, Andreasen JT, Weikop P, Mirza M, Scheel-Krüger J, Mikkelsen JD. The neuronal KCNQ channel opener retigabine inhibits locomotor activity and reduces forebrain excitatory responses to the psychostimulants cocaine, methylphenidate and phencyclidine. Eur $J$ Pharmacol. 2007;570(1-3):77-88.
45. Richter A, Sander SE, Rundfelt C. Antidystonic effects of $\mathrm{K}_{v} 7$ (KCNQ) channel openers in the $d t^{s z}$ mutant, an animal model of primary paroxysmal dystonia. Br J Pharmacol. 2006;149(6):747-753.

46. Korsgaard MP, Hartz BP, Brown WD, Ahring PK, Strøbaek D, Mirza NR. Anxiolytic effects of Maxipost (BMS-204352) and retigabine via activation of neuronal Kv7 channels. J Pharmacol Exp Ther. 2005;314(1):282-292.

47. Ng FL, Davis AJ, Jepps TA, et al. Expression and function of the $\mathrm{K}+$ channel KCNQ genes in human arteries. Br J Pharmacol. 2011;162(1):42-53.

48. Joshi S, Sedivy V, Hodyc D, Herget J, Gurney AM. KCNQ modulators reveal a key role for KCNQ potassium channels in regulating the tone of rat pulmonary artery smooth muscle. J Pharmacol Exp Ther. 2009;329(1): $368-376$.

\section{Publish your work in this journal}

Drug, Healthcare and Patient Safety is an international, peer-reviewed open-access journal exploring patient safety issues in the healthcare continuum from diagnostic and screening interventions through to treatment, drug therapy and surgery. The journal is characterized by the rapid reporting of reviews, original research, clinical, epidemiological and post-marketing surveillance studies, risk management, health literacy and educational programs across all areas of healthcare delivery. The manuscript management system is completely online and includes a very quick and fair peer-review system. Visit http://www.dovepress.com/ testimonials.php to read real quotes from published authors. 